\title{
Clinicopathologic Results in Meniere Disease: Evaluation of 80 patients
}

\author{
Mehmet Sürmeli, $\odot$ ildem Deveci
}

Department of Otolaryngology, Science of Health University, Umraniye Training and Research Hospital, Istanbul, Turkey

\begin{abstract}
Introduction: Meniere's disease is the second most common disease among peripheral vestibular diseases. However, clinicopathology and treatment of Meniere's disease are not yet fully understood. In this study we aimed to investigate the relationship between the demographic features, audiological findings and treatment modalities of the Meniere's disease.

Methods: Demographic characteristics, additional diseases, pure audio audiometric test results and treatment modalities of 80 patients with Meniere's disease were compared retrospectively with statistical methods.

Results: The study involved 54 (67.5\%) female, and 26 (32.5\%) male patients with an average age of 47.5 \pm 12.0 .54 . Right ear was affected in 31 (38.8\%) patients, left ear in 38 (47.5\%) patients, and both ears in $11(13.8 \%)$ patients. The most common comorbid diseases were diabetes mellitus $(n=11)$ and hypothyroidism $(n=11)$. The average hearing threshold values of 250-

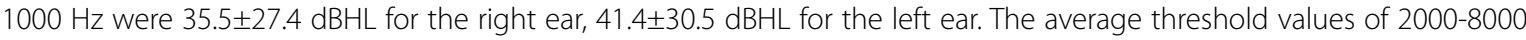
$\mathrm{Hz}$ were $36.9 \pm 29.6 \mathrm{dBHL}$ for the right ear and $45.7 \pm 31.4 \mathrm{dBHL}$ for the left ear. There was no statistically significant difference between low and high frequencies in right and left ear $(p=0.84, p=0.073)$. To fix vertigo 35 (43.8\%) patients received medical treatment, 17 (21.2\%) patients treated with transtympanic steroid ablation, and 28 (35.0\%) patients treated with transtympanic gentamycin ablation.

Discussion and Conclusion: The prolongation of diagnosis time in Meniere's disease induces additional impairment of highfrequency hearing and also causes difficulties in the diagnosis

Keywords: Hearing loss; meniere's disease; peripheral vertigo.
\end{abstract}

$\mathrm{M}$ eniere's disease is a membranous labyrinthitis with an iidopathic onset and characterized with episodic vertigo attacks accompanied by fluctuating hearing loss, tinnitus and aural fullness. Its incidence in population in general is around 190/100000 [1]. Pathophysiologically it is characterized by endolymphatic hydrops manifesting in the membranous labyrinth. Hydrops is generally localized in cochlear canal or saccule, it may also involve utriculus or semicircular canals as well ${ }^{[2]}$.
Anatomic, genetic, immunological, viral, vascular, metabolic, psychological factors are held responsible for the pathogenesis of the disease ${ }^{[3]}$. The diagnostic guide was first published by the American Academy of Otolaryngology-Head and Neck Surgery Committee on Hearing and Equilibrium (AAOHNS-CHE) in 1972 and revised by the Classification Committee of the Barany Society (CCBS) in $2015^{[4]}$. The parameters used for the diagnostic criteria are mostly based on subjective data and are examined in two sub-sections ${ }^{[4]}$;

Correspondence (iletişim): Mehmet Sürmeli, M.D. Department of Otolaryngology, Science of Health University, Umraniye Training and Research Hospital, Istanbul, Turkey

Phone (Telefon): +90 2166321818 E-mail (E-posta): drsurmelimehmet@gmail.com

Submitted Date (Başvuru Tarihi): 02.03.2018 Accepted Date (Kabul Tarihi): 17.04.2018 


\section{Definite Meniere's Disease:}

- Two or more vertigo attacks that last $20 \mathrm{~min}$ to 12 hours.

- Sensorineural hearing loss from low frequencies to medium frequencies documented during or after vertigo attacks

- Fluctuating aural symptoms in the affected ear (hearing loss, tinnitus, fullness)

- It should be verified that there are no vestibular diseases that may cause these complaints.

\section{Possible Meniere's Disease:}

- Two or more episodes of vertigo or dizziness lasting 20 minutes to 24 hours

- Fluctuating aural symptoms in the affected ear (hearing loss, tinnitus, fullness)

- It should be verified that there are no vestibuler diseases that may cause these complaints.

Diagnosis of vestibular system diseases are delayed due to insufficient recognition of the disease and the inability of patients to correctly describe their complaints. These delays in diagnosing the disease cause the hearing loss to become more pronounced at high frequencies. It is clear that diagnosing the disease will be increasingly difficult when the diagnosis is based on the diagnostic criteria in the late stages of the disease. As a result, the exact diagnosis of the disease becomes increasingly difficult. Diagnostic delay also indirectly affects treatment success.

In this study, we aimed to investigate the demographic features, audiological findings and treatment approaches of the cases followed up with the diagnosis of Meniere's disease in our clinic.

\section{Materials and Methods}

This study was performed in the the ear, nose and throat diseases clinic of our hospital. For the study, approval from our hospital Ethics Committee was obtained.

A retrospective analysis of 80 patients with Meniere's disease diagnosed according to the Meniere's Disease Diagnostic Criteria published by the Classification Committee of the Barany Society (CCBS) between January 2015 and December 2017 was conducted.

Eighty patients included in the study were questioned for age, sex, and accompanying additional diseases. The ear and/or ears affected by the disease, the onset time of the disease, and the pure voice odometric test results were separately calculated separately for the right and left ears, within a range of $250-8000 \mathrm{~Hz}$. In addition to these findings, treatment approaches applied to the disease were recorded.

\section{Statistical Analysis}

SPSS version 20 program (SPSS, IBM Corporation; Armonk, NY, USA) was used for statistical analysis of the data obtained from the study Descriptive statistical analyzes were performed. Variance analysis of the data obtained from the study was performed with the Kolmogorow-Smirnov test. Mann-Whitney $U$ test was used for the evaluation of nonnormal distribution of binary data, and Independent-Sample t Test was used for the evaluation of binary distributions fitting to normal distribution. Statistical significance level was considered as $p<0.05$.

\section{Results}

The mean age of 80 patients included in the study was $47.5 \pm 12.0$ years, while $67.5 \%(n=54)$ of the patients were female and $32.5 \%(n=26)$ of them were male. The mean ages of the male and female patients included in the study were $48.22 \pm 11.24$, and $46.0 \pm 13.73$ years, respectively (Table 1). There was no statistical significance between the mean age of men and women ( $p>0.05$ ) (Fig. 1). When the data of the existing patients were examined, the most common accompanying disease was diabetes mellitus and hypothyroidism that were found 11 patients. Other accompanying diseases are presented in Table 2.

When the affected ears of the patients included in the study were examined, it was found that Meniere's disease affected right $(n=31: 38.8 \%)$, left $(n=38: 47.5 \%)$ and both ears $(n=11: 13.8 \%)$ in indicated number of patients. When

Table 1. Demographic characteristics of the patients with Meniere's disease $(n=80)$

\begin{tabular}{lc}
\hline Demographic characteristics & $\mathbf{n = 8 0}$ \\
\hline Gender (F/M); & $54 / 26$ \\
Age (year) & \\
$\quad$ Mean \pm SD & $47.5 \pm 12.06$ \\
$\quad$ Median (Min-Max) & $49(17-71)$ \\
Affected side (\%) & \\
$\quad$ Right & $31(38.8)$ \\
$\quad$ Left & $38(47.5)$ \\
$\quad$ Bilateral & $11(13.8)$ \\
Time to diagnosis (year) & \\
$\quad$ Mean $\pm S D$ & $5.43 \pm 5.21$ \\
$\quad$ Median (Min-Max) & $4(1-26)$ \\
\hline
\end{tabular}

SD: Standard Deviation; Min: Minimum, Max: Maximum. 
the time from the onset of the disease to its diagnosis was evaluated, the average time to diagnosis was calculated as $5.43 \pm 5.21$ years. According to gender, when the time to diagnosis was examined in detail, it was $5.30 \pm 4.85$ years for women and $5.69 \pm 5.99$ years for men. There was no statistically significant difference between the time to diagnosis according to gender ( $p>0.05$ ) (Table 1, Fig. 2).

Pure audiometry data of the patients were analyzed within a frequency range of $250-8000 \mathrm{~Hz}$. Average hearing thresholds were calculated for each frequency (Figs. 3, 4). All of the patients had sensorineural hearing loss. Within the frequency range of $250-1000 \mathrm{~Hz}$, the threshold of hearing threshold was $35.5 \pm 27.4 \mathrm{dBHL}$ for the rightand $41.4 \pm 30.5$ $\mathrm{dBHL}$ for the left ear.

However, when the high frequencies were examined $(2000-8000 \mathrm{~Hz})$, the hearing threshold was measured as $36.9 \pm 29.6 \mathrm{dBHL}$ in the right ear and $45.7 \pm 31.4 \mathrm{dBHL}$ in the left ear. Low frequency and high frequency losses after the pure tone audiometry examinations of the right and left ears were examined statistically. There was no statistically significant difference between between low and high frequencies in the right and left ears $(p=0.84, p=0.073)$.

Thirty-five patients $(43.8 \%)$ were followed-up with medical treatment while 45 patients (56.2\%) received medical treatment plus transtympanic ablative treatments. Transtympanic gentamicin ablation therapy was applied to $28(35.0 \%)$ of the patients while 17 patients $(21.2 \%)$ were treated with transtympanic steroids as ablative therapy (Table 3). After the treatments applied, vertigo all of the patients was kept under control.

\section{Discussion}

Meniere's disease is the second most common disease among all peripheral vestibular system diseases ${ }^{[5]}$. Although the first patient was reported by Prosper Meniere in 1861, the pathophysiology, clinicopathology and treatment of the disease have not been fully elucidated yet.

Meniere's disease is most commonly seen in adult subjects aged $30-60$ years ${ }^{[6]}$. The incidence in children under 15 years is $0.4-7.0 \%{ }^{[7]}$. In childhood, it usually occurs as secondary to congenital diseases ${ }^{[8]}$. In our study, the average age range of our cases was between 35 and 60 years. Our youngest case of Meniere's disease was 17 years old. There was no difference in age distribution between males and females.

Meniere's disease is more frequently seen in women than in men. In a study by Harris JP et al. ${ }^{[1]}$ male to female ra-
Table 2. Comorbid diseases in patients with Meniere's disease

\begin{tabular}{llc}
\hline Disease & N & \% \\
\hline Diabetes mellitus & 11 & 13.75 \\
Hypothyroidism & 11 & 13.75 \\
Hypertension & 7 & 8.75 \\
Asthma & 6 & 7.5 \\
Coronary artery disease & 4 & 5.0 \\
Rheumatoid arthritis & 2 & 2.5 \\
Acute rheumatic fever & 2 & 2.5 \\
Tumors & 5 & 6.25 \\
$\quad$ I. Olfactory neuroblastoma & 1 & \\
$\quad$ II. Over Ca & 1 & \\
$\quad$ III. Breast Ca & 1 & \\
IV. Pituitary adenoma & 2 & \\
\hline
\end{tabular}

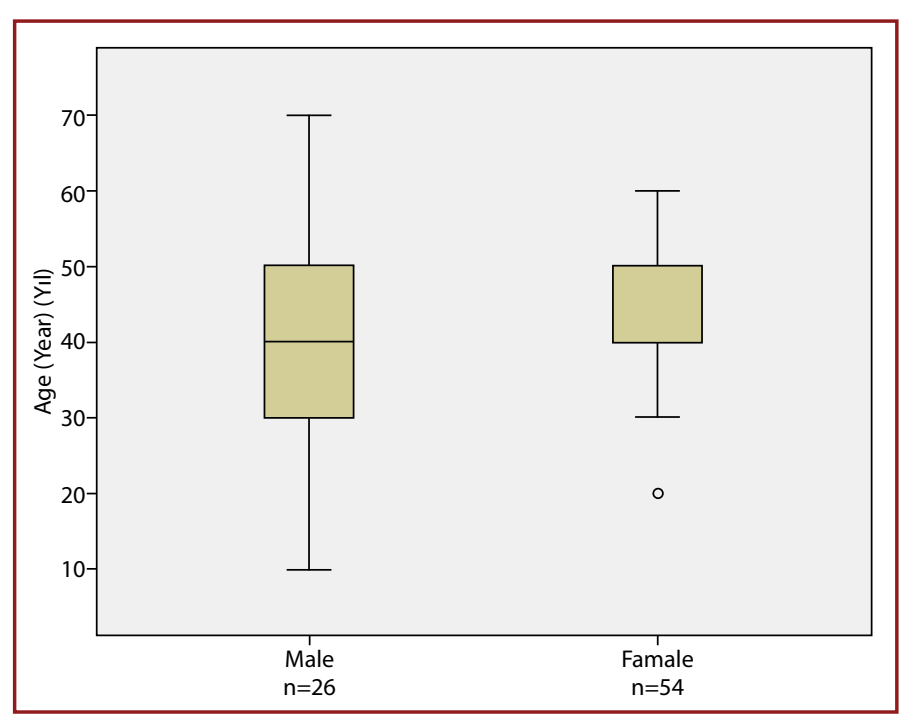

Figure 1. Age and gender distribution in Meniere's disease.

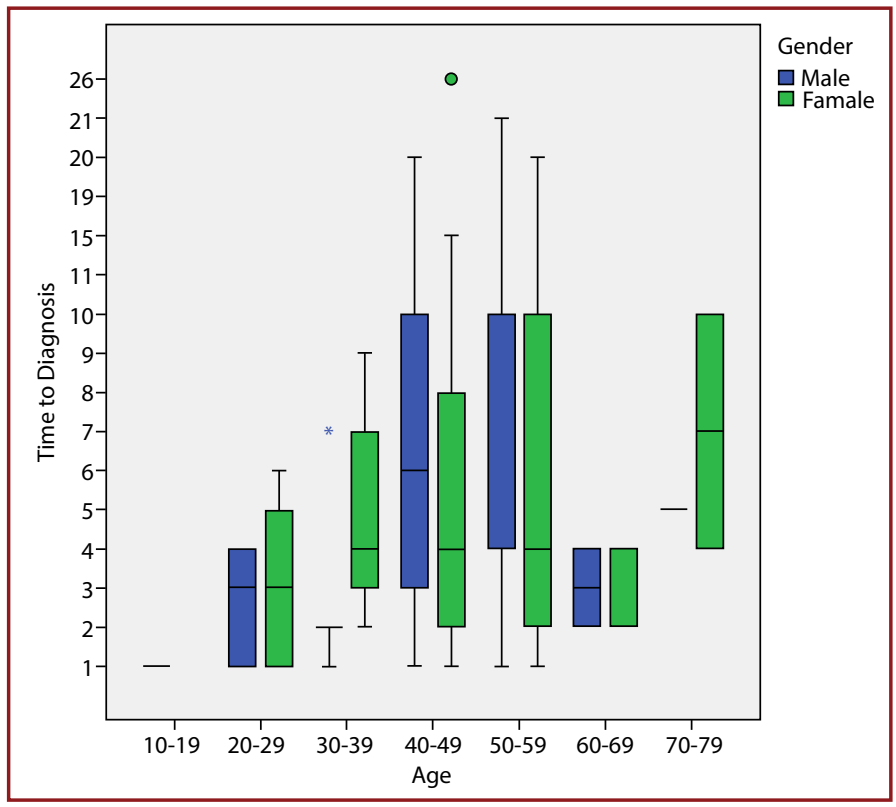

Figure 2. Relationship between age and gender in the diagnosis of Meniere's disease. 


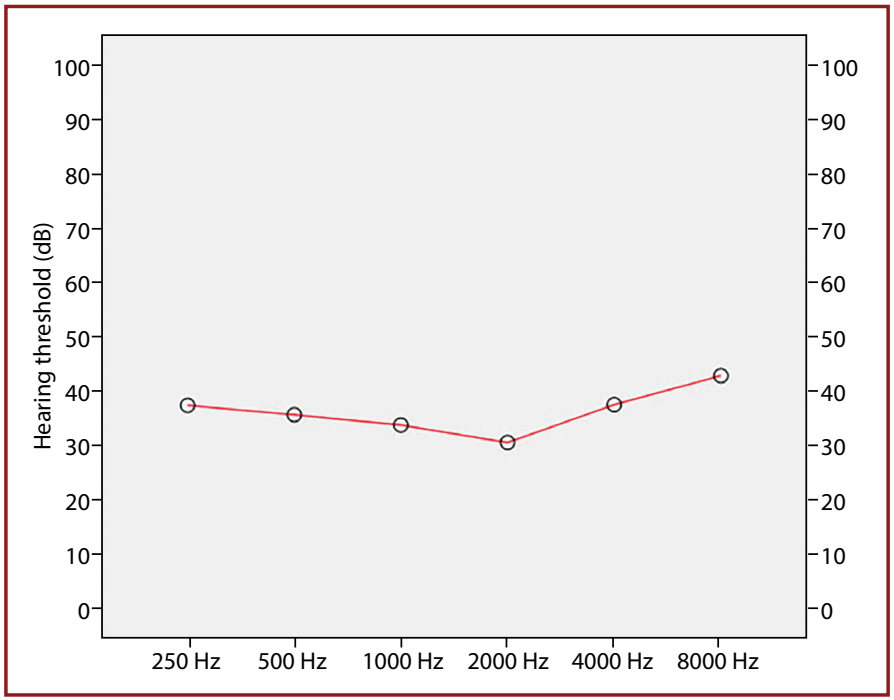

Figure 3. Hearing thresholds of the right ear in Meniere's disease.

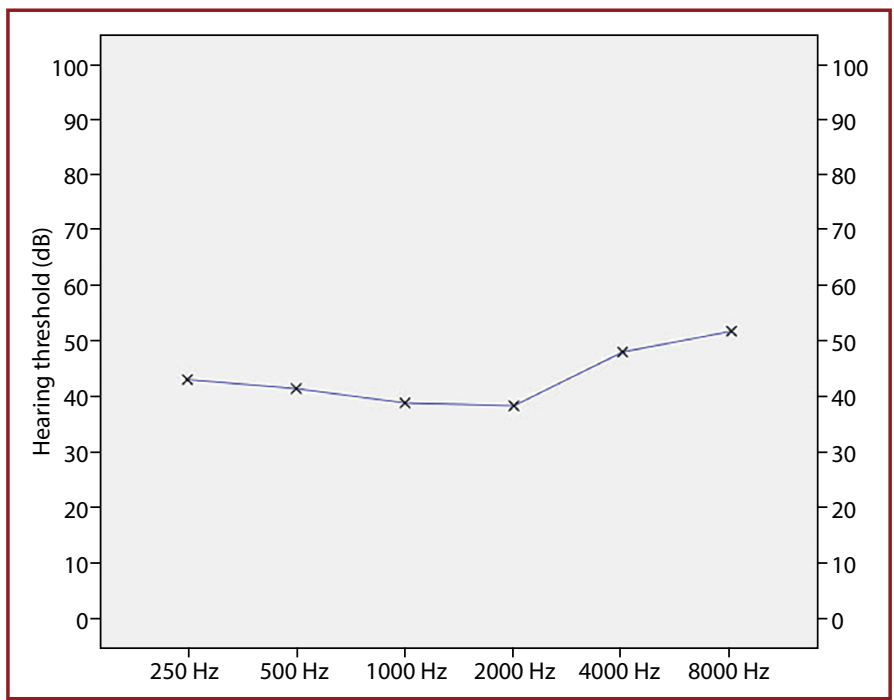

Figure 4. Hearing thresholds of the left ear in Meniere's disease.

tio in Meniere's disease was $1.89 / 1$. This ratio was found as $1.3 / 1$ by Shojaku H. et al., ${ }^{[9]}$ and $2.31 / 1$ by Yin M. et al. ${ }^{[6]}$. In our study, we found that Meniere's disease was seen more frequently in women than in men. Female to male in our study was found to be $2.07 / 1$.

Bilateral involvement in Meniere's disease ranges from $10 \%$ to $35 \%$. Paparella et al. ${ }^{[10]}$ found that bilateral involvement in Meniere's disease was 14\%. The incidence of bilateral involvement was detected as $27 \%$ by Friedrichs et al., ${ }^{[11]}$ and as $5 \%$ by Perez et al. ${ }^{[12]}$. In our study, bilateral involvement in Meniere's disease was found to be $13.8 \%$. There was no difference between left and right ear involvement.

Today, the most important diagnostic method for Meniere's disease is still pure-tone audiometry test. During diagnos-
Table 3. Treatment approaches in Meniere's disease $(n=80)$

\begin{tabular}{lcc}
\hline Treatment & $\mathbf{n = 8 0}$ & \% \\
\hline Medical Treatment & 35 & 43.8 \\
Transtympanic Steroid & 17 & 21.2 \\
Transtympanic Gentamicin & 28 & 35.0 \\
Total & 80 & 100.0 \\
\hline
\end{tabular}

tic evaluation, sensorineural-type hearing loss accompanying by at least 2 episodic vertigo attacks lasting between 20 minutes and 12 hours is considered adequate for definitive diagnosis of meningioma ${ }^{[4]}$.

However, this method has some difficulties in terms of diagnostic examination. In our study, the average duration of delay for diagnosis was 5.43 years. Because of this delay in diagnosis, the pure-tone audiometry test, which is necessary for diagnosis, is affected by the disease at high frequency in addition to low and medium frequencies. In our study, no statistically significant difference was found between hearing loss levels detected at low frequencies (250-1000 Hz) and at high frequencies $(2000-8000 \mathrm{~Hz})$. There is currently no consensus among the treatment approaches of Meniere's disease. Among the three main symptoms of the disease vertigo disturbs the patients the most severely. Treatment approaches are mostly based on vertigo control and protection of the existing hearing acuity. Diet modifications, daily life style modification, prophylactic treatments, surgical or ablative treatments are the most frequently used approaches in the current treatment of the disease.

Dietary modifications and regulation of daily life are frequently applied as a preventive approach in Meniere's disease. Diet and life style modifications such as low-salt diet (1.5 gr/day), restriction of theophylline, and caffeine containing products (tea, coffee, cola, chocolate etc.), prohibition of smoking, and weight gain, prevention of sedentary life and heavy exercises were applied for all patients.

The most commonly used molecule in medical treatment is betahistine. Betahistine plays an active role in the treatment of Meniere's disease through its immunoregulatory mechanism of action at a molecular level by inducing vasodilatation over $\mathrm{H} 3$ receptors with its antagonistic effect, and over $\mathrm{H} 1$ receptors with its agonistic effect ${ }^{[13]}$. However, Tootoonchi SJS et al. ${ }^{[14]}$ found that daily doses of 48 $\mathrm{mg}$ betahistine were effective in the preservation of hearing acuity. In our clinic as medical treatment betahistine is initiated for all patients with established diagnosis of Meniere's disease at daily oral doses of $48 \mathrm{mg}$. 
In $43.8 \%$ of the patients with Meniere's disease, vertigo was controlled with betahistine at $48 \mathrm{mg} /$ day without any additional treatment. Despite dietary modification and medical treatment, additional treatments are needed in cases where disease control can not be achieved. The most frequently applied ones are surgical (endolymphatic sac decompression procedure, labyrinthectomy, vestibular neurectomy) and transtympanic ablative (steroid, and gentamicin) treatments.

Labyrinthectomy and vestibular neurectomy are successful in the control of Meniere's disease in almost all (95\%) of the cases ${ }^{[15]}$. However, labyrinthectomy causes total hearing loss and vestibular neurectomy requires craniotomy and causes serious morbidity. On the other hand, since ablative treatments have about the same success rates with low morbidity rates, nowadays surgical treatment approaches to Meniere's disease are applied less frequently, and ablative treatments are replacing surgical treatments ${ }^{[15]}$.

Nowadays, steroids (dexamethasone and prednisolone) and gentamicin (aminoglycosides) are the most commonly used medications in trantimpanic ablation ${ }^{[15]}$. Although there was no statistical difference in short-term follow-ups of steroid and gentamicin on vertigo control in Meniere's disease, gentamicin was found to be statistically significantly more effective in controlling vertigo in long-term (2-year) follow-ups ${ }^{[16]}$. The most important complication of gentamicin ablation is hearing loss. Although steroid ablation is less effective than gentamicin ablation on vertigo control, it has been found to be more effective in preserving auditory and vestibular functions ${ }^{[17]}$. However, it has been shown that low doses of gentamicin maintains hearing functions longer when compared with its high dose administration ${ }^{[18]}$.

In the study we performed, $21.2 \%$ of our patients were treated with transtympanic steroid ablation in addition to medical treatment and in $35.0 \%$ of the cases in addition to medical treatment low-dose transtympanic gentamicin ablation was used to control vertigo.

\section{Conclusion}

Although Meniere's disease is an important disease among causes peripheral vertigo, a consensus on its diagnostic examinations and treatment approaches hase not been formulated yet. Due to inadequate recognition of the disease, the diagnosis of the disease is delayed and therefore the classical hearing profile that is expected for the diagnostic examination can not be detected in patients.
Ethics Committee Approval: The approval of the local Ethics Committee was obtained.

Peer-review: Externally peer-reviewed.

Authorship Contributions: Concept: M.S.; Design: M.S.; Data Collection or Processing: M.S., I.D.; Analysis or Interpretation: M.S.; Literature Search: I.D., M.S.; Writing: I.D., M.S.

Conflict of Interest: None declared.

Financial Disclosure: The authors declared that this study received no financial support.

\section{References}

1. Harris JP, Alexander TH. Current-day prevalence of Ménière's syndrome. Audiol Neurootol 2010;15:318-22. [CrossRef]

2. Merchant SN, Rauch SD, Nadol JB Jr. Ménière's disease. Eur Arch Otorhinolaryngol 1995;252:63-75. [CrossRef]

3. Saeed SR. Fortnightly review: Diagnosis and treatment of Ménière's disease. BMJ 1998;316:368-72. [CrossRef]

4. Lopez-Escamez JA, Carey J, Chung WH, Goebel JA, Magnusson $\mathrm{M}$, Mandalà $\mathrm{M}$, et al; Classification Committee of the Barany Society; Japan Society for Equilibrium Research; European Academy of Otology and Neurotology (EAONO); Equilibrium Committee of the American Academy of Otolaryngology-Head and Neck Surgery (AAO-HNS); Korean Balance Society.Diagnostic criteria for Menière's disease. J Vestib Res 2015;25:1-7.

5. Ljunggren M, Persson J, Salzer J. Dizziness and the Acute Vestibular Syndrome at the Emergency Department: A Population-Based Descriptive Study. Eur Neurol 2017;79:5-12.

6. Yin M, Ishikawa K, Wong WH, Shibata Y. A clinical epidemiological study in 2169 patients with vertigo. Auris Nasus Larynx 2009;36:30-5. [CrossRef]

7. Choung $\mathrm{YH}$, Park K, Kim CH, Kim HJ, Kim K. Rare cases of Ménière's disease in children. J Laryngol Otol 2006;120:34352. [CrossRef]

8. Wang C, Wu CH, Cheng PW, Young YH. Pediatric Meniere's disease. Int J Pediatr Otorhinolaryngol 2018;105:16-9. [CrossRef]

9. Shojaku H, Watanabe $Y$, Fujisaka M, Tsubota M, Kobayashi K, Yasumura $S$, et al. Epidemiologic characteristics of definite Ménière's disease in Japan. A long-term survey of Toyama and Niigata prefectures. ORL J Otorhinolaryngol Relat Spec 2005;67:305-9. [CrossRef]

10. Paparella MM, Mancini F. Vestibular Meniere's disease. Otolaryngol Head Neck Surg 1985;93:148-51. [CrossRef]

11. Friedrichs I, Thornton AR. Endolymphatic hydrops in asymptomatic ears in unilateral Ménière's disease. Laryngoscope 2001;111:857-60. [CrossRef]

12. Perez R, Chen JM, Nedzelski JM. The status of the contralateral ear in established unilateral Menière's disease. Laryngoscope 2004;114:1373-6. [CrossRef]

13. Møller MN, Kirkeby S, Vikeså J, Nielsen FC, Caye-Thomasen P. Expression of histamine receptors in the human endolymphatic sac: the molecular rationale for betahistine use in $\mathrm{Me}$ nieres disease. Eur Arch Otorhinolaryngol 2016;273:1705-10. 
14. Seyed Tootoonchi SJ, Ghiasi S, Shadara P, Samani SM, Fouladi DF. Hearing function after betahistine therapy in patients with Ménière's disease. Braz J Otorhinolaryngol 2016;82:500-6.

15. Syed MI, Ilan O, Leong AC, Pothier DD, Rutka JA. Ménière's Syndrome or Disease: Time Trends in Management and Quality of Evidence Over the Last Two Decades. Otol Neurotol 2015;36:1309-16. [CrossRef]

16. Casani AP, Piaggi P, Cerchiai N, Seccia V, Franceschini SS, Dallan I. Intratympanic treatment of intractable unilateral Meniere disease: gentamicin or dexamethasone? A randomized controlled trial. Otolaryngol Head Neck Surg 2012;146:430-7.

17. Syed MI, Ilan O, Nassar J, Rutka JA. Intratympanic therapy in Meniere's syndrome or disease: up to date evidence for clinical practice. Clin Otolaryngol 2015;40:682-90. [CrossRef]

18. Watson GJ, Nelson C, Irving RM. Is low-dose intratympanic gentamicin an effective treatment for Ménière's disease: the Birmingham experience. J Laryngol Otol 2015;129:970-3. 